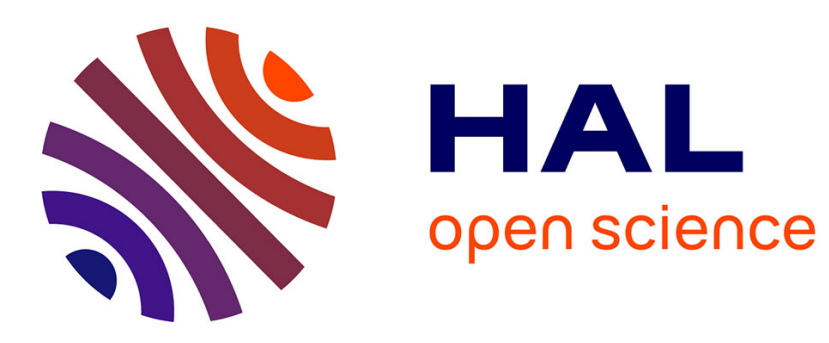

\title{
Titration of apparent in-cellula affinities of protein-protein interactions
}

David Cluet, Blandine Vergier, Nicolas-Pierre Levy, Lucie Dehau, Alexandre Thurman, Ikram Amri, Martin Spichty

\section{- To cite this version:}

David Cluet, Blandine Vergier, Nicolas-Pierre Levy, Lucie Dehau, Alexandre Thurman, et al.. Titration of apparent in-cellula affinities of protein-protein interactions. ChemBioChem, In press, 23 (4), pp.e202100640. 10.1002/cbic.202100640 . hal-03026557v2

\section{HAL Id: hal-03026557 \\ https://hal.science/hal-03026557v2}

Submitted on 22 Dec 2021

HAL is a multi-disciplinary open access archive for the deposit and dissemination of scientific research documents, whether they are published or not. The documents may come from teaching and research institutions in France or abroad, or from public or private research centers.
L'archive ouverte pluridisciplinaire HAL, est destinée au dépôt et à la diffusion de documents scientifiques de niveau recherche, publiés ou non, émanant des établissements d'enseignement et de recherche français ou étrangers, des laboratoires publics ou privés. 


\section{Titration of apparent in-cellula affinities of protein- 2 protein interactions}

David Cluet, ${ }^{1}$ Blandine Vergier, ${ }^{1}$ Nicolas-Pierre Levy, ${ }^{1}$ Lucie Dehau, ${ }^{1}$ Alexandre Thurman, ${ }^{1}$ Ikram Amri ${ }^{1}$ and Martin Spichty ${ }^{2 \#}$

1) Laboratoire de Biologie et de Modélisation de la Cellule, Ecole Normale Supérieure de Lyon, CNRS, Université Lyon 1, Université de Lyon; 46 allée d'Italie; 69364 Lyon cedex 07; France. 2) Laboratoire d'Innovation Moléculaire et Applications, Université de Strasbourg - Centre National de la Recherche Scientifique - Université de Haute-Alsace, 3 bis rue Alfred Werner, 68057 Mulhouse Cedex, France.

\#) corresponding author. Phone: +33 3893368 62; Email: martin.spichty@uha.fr.

\section{Graphical abstract:}

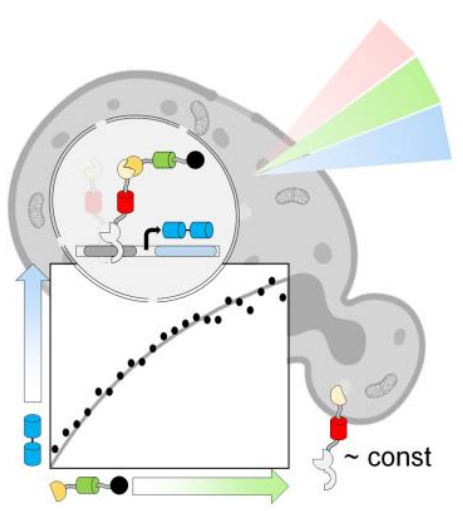

Using fluorescent probes, we estimate at the cellular level the fraction of Bait molecules bound by Prey molecules in a quantitative yeast-two hybrid assay. A titration-like analysis of flow cytometer data permits the extraction of the apparent in-cellula dissociation constant.

KEYWORDS: protein-protein interactions, quantitative yeast-two hybrid, flow cytometry, single-cell analysis. 
Abstract: A genetic assay permits simultaneous quantification of two interacting proteins and their bound fraction at the single-cell level using flow cytometry. Apparent in-cellula affinities of protein-protein interactions can be extracted from the acquired data through a titration-like analysis. The applicability of this approach is demonstrated on a diverse set of interactions with proteins from different families and organisms and with in-vitro dissociation constants ranging from picomolar to micromolar. (Introduction)

The quest for methods that permit rapid and reliable determination of the affinity of protein-protein interactions (PPI) is unbroken. In contrast to biochemical in-vitro methods such as Isothermal Titration Calorimetry (ITC) and Surface Plasmon Resonance (SPR) that require purified proteins, quantitative genetic assays rely on the expression of the proteins of interest in cells. Many of these assays ${ }^{[1-6]}$ are inspired by the yeast two-hybrid (Y2H) technique ${ }^{[7-9]}$ which is based on the in-cellula expression of two proteins, usually named Bait and Prey, fused to an DNA-binding domain (BD) and an activation domain (AD), respectively. Upon physical interaction of the BD-Bait and AD-Prey proteins, a functional transcription factor is reconstituted that drives the expression of a reporter gene. The stronger the interaction, the higher should be the expression level of the reporter. ${ }^{[1]}$ However, the expression level of the BD-Bait and AD-Prey play an important role, too. ${ }^{[10]}$

We recently introduced a quantitative yeast-two hybrid system (qY2H) that permits for the first time simultaneous quantification of BD-Bait, AD-Prey and the reporter at the singlecell level without the need of any antibodies or purified proteins. ${ }^{[10]}$ Instead, we take advantage of fluorescent fusion proteins that can be detected by standard flow cytometers. Here we show how this qY2H method can be exploited to perform a titration-like analysis to extract the apparent in-cellula affinity of PPIs by applying the following two important improvements: 
1) Cellular contents of fluorescent proteins are determined in units of Molecules of

Equivalent Soluble Fluorochrome (MESF), so that measured quantities become independent of the applied apparatus setup. It facilitates the future transferability of the qY2H measurements to other flow cytometers and allows researchers to consistently compare their results.

2) The cultured populations of yeast cells can be considered as collections of microvessells ${ }^{[11]}$ with distinctly different content of BD-Bait, AD-Prey and reporter. The fluorescence data of these collections can be analyzed by a titration-like procedure. This allows the straightforward extraction of apparent in-cellula dissociation constants for BD-Bait:ADPrey interactions.

In a proof of concept, we apply this in-cellula titration approach to a diverse set of PPIs with dissociation constants ranging from $117 \mathrm{pM}$ to $17 \mu \mathrm{M}$ (Table 1). We consider the set of Table 1 as an ideal choice for mainly three reasons: a) the set covers a wide range of affinities, protein families and protein sizes; b) when fused to BD-or AD-, the proteins do not display any detectable auto-activation under the applied experimental conditions; ${ }^{[10]} \mathrm{c}$ ) all PPIs have been extensively studied in-vitro (see footnotes of Table 1). As in in-vitro SPR experiments, each PPI can be measured by $\mathrm{Y} 2 \mathrm{H}$ in two different orientations (by exchanging the proteins between BD-Bait and AD-Prey). Here we study only the orientation that produced the higher reporter level. ${ }^{[10]}$ This orientation is considered as the molecular configuration with the higher accessibility of the PPI binding interface..$^{[1]}$

\section{(Methodology)}

In our qYH2 experiments, diploid yeast cells with constitutive expression of BD-Bait and induced expression of AD-Prey are cultured for two hours. Then, their fluorescence intensity is measured by flow cytometry in the three channels TagRFP-H (corresponding to BD-Bait), EGFP-H (AD-Prey), and TagBFP-H (reporter). Due to phenotypic variations, BDBait and AD-Prey are expressed at different levels among these cells which can be exploited to 
"prepare samples" for a titration-like analysis. By gating, we can split the global heterogeneous ensemble of cells into several homogenous subensembles (bins). Each bin contains only cells within two specific, narrow intervals of red and green fluorescence intensity centered at values $R$ and $G$, respectively. Assuming a linear relationship between fluorescence intensity and molecule numbers, $R$ and $G$ can be considered as measures for the mean cellular content of BDBait and AD-Prey in the corresponding bin. Cellular contents of fluorescent proteins are determined in units of Molecules of Equivalent Soluble Fluorochrome (MESF), so that measured quantities become independent of the applied apparatus setup. It facilitates the future transferability of the qY2H measurements to other flow cytometers and allows researchers to consistently compare their results.

With the mean value of the blue fluorescence intensity, we can calculate for each bin the normalized reporter level $\varphi$. It is obtained by forming the ratio of the expression level for the interaction of interest, $E_{\text {interaction }}$ (Fig. 1A) and the level for a covalent BD-AD fusion, $E_{\text {colvalent }}$ (Fig. 1B). This normalization renders $\varphi$ dimensionless and independent of the acquisition apparatus (assuming again a linear relationship between molecule number and fluorescence intensity). Most importantly, we consider that $\varphi$ reflects the time-averaged fraction of BD-Bait bound by AD-Prey during the reaction (as explained in the caption of Fig. 1). Thus, titration curves can be obtained when $\varphi$ is plotted as a function of $G$ while keeping $R$ fixed (Fig. 1C). The curves can be fitted with the following Langmuir-type equation:

$$
\varphi(G) \cong \beta \frac{G / \alpha}{K_{\mathrm{d}}^{\prime}+R+G / \alpha}
$$

where $K^{\prime}{ }_{\mathrm{d}}$ is the apparent in-cellula dissociation constant (in units of MESF of EGFP) and $\alpha$ and $\beta$ are dimensionless parameters that empirically account for the fact that $\varphi$ is a timeintegrated property. The parameter $\alpha$ reduces the final cellular content of AD-Prey (measured 
at the end of the reaction, $G$ ) to the time-averaged content (over the entire reaction course,

$114\left\langle G>\right.$ ). Since the induction kinetics under the GAL1-promoter in yeast ${ }^{[12]}$ displays a quadratic-

115 like time dependence (for short induction times), a reasonable choice for $\alpha$ is $3\left[\langle G\rangle={ }_{0} \int^{1} G t^{2}\right.$

$116 d t=G / 3$ ]. The prefactor $\beta$, on the other hand, integrates differences in the expression kinetics

117 of the reporter for $E_{\text {interaction }}$ (induced expression) and $E_{\text {covalent }}$ (constitutive expression). It can

118 be determined experimentally by monitoring $\varphi$ for $G \rightarrow \infty$ using a high-affinity couple (such 119 as BD-Barstar29F/AD-BarnaseH102A).

120 We recommend that the titration-like analysis is carried out with the lowest possible 121 value of $R=R_{\min }$ (as defined by the detection limit of TagRFP by flow cytometry, see 122 "Methods"). It limits overexpression and associated protein burden effects. ${ }^{[13]}$ Furthermore, the 123 auto-activation potential of the BD-Bait fusion is kept at a minimum, too. ${ }^{[14]}$ Most importantly,

124 it mimics the condition of in-vitro affinity titration experiments ${ }^{[15]}$ where the concentration of 125 the titrated species (here BD-Bait) is kept fixed and as low as possible to avoid saturation 126 effects. For the titrations with $R=R_{\min }$ the parameters $\alpha=3$ and $\beta=1.35$ were used to extract the $127 K^{\prime}{ }^{\prime}$-values.

128 Our in-cellula assay differs significantly from in-vitro titration experiments (as 129 previously discussed ${ }^{[10]}$ in detail). The in-vitro experiment measures the affinity under well130 defined buffer-controlled equilibrium conditions. In contrast, our in-cellula experiments take 131 place in a non-equilibrium biological environment ${ }^{[11]}$ where the interaction partners BA-Bait 132 and AD-Prey can interact with the endogenous complex solution of biomolecules. This may 133 lead, for example, to effectively smaller concentrations of the reaction partners. The measured 134 in-cellula dissociation constant should therefore be perceived as an apparent dissociation 135 constant. Also, only bimolecular interactions can be investigated with the in-cellula approach.

\section{6 (Results and Discussion)}

137 Despite the substantial differences between our in-cellula system and in-vitro setups, 
138 the apparent in-cellula affinities strongly correlate with those from in-vitro measurements

$139\left(\mathrm{R}^{2}=0.91\right.$, Fig. 1D). The slope of the regression line in the log-log plot of the dissociation

140 constants is 0.84 . Other in-cellula assays usually find lower Pearson correlation coefficients $(<$

$1410.9)$ and significantly lower values for the slope of the regression line (0.2-0.6). ${ }^{[4,5,16-18]}$ This is

142 even more remarkable if one considers that the tested set of PPIs in this work is significantly

143 more diverse. The regression slope in the log-log plot indicates the power law between the in-

144 cellula quantity and the in-vitro quantity. If the apparent in-cellula affinity was linearly

145 correlated with in-vitro affinity, we would observe a value of 1 for the regression slope. A

146 decrease of the regression slope in the log-log plot (in-cellula vs in-vitro) potentially points to

147 a decreased sensitivity of the cellular assay: the extent of the BD-Bait:AD-Prey affinity has

148 little impact on the read-out of the cellular assay, i.e., the read-out is largely dominated by

149 cellular processes that do not depend on the affinity between BD-Bait and AD-Prey. Thus, the

150 higher regression slope in the case of our qY2H titration approach (with respect to other in-

151 cellula assays) may indicate a higher sensitivity; more testing will be necessary to confirm this

152 surmise.

153 From the regression analysis (intercept) it is possible to derive a rough estimate for the

154 conversion factor that relates units of MESF of $K^{\prime}$, in-cellula to units of molarity. With the relation

$155150 \mathrm{MESF} \approx 1 \mathrm{pM}$; appropriate values in units of molarity are obtained (Table S1, Supporting

156 Information). This conversion relies on the assumption that the in-cellula affinities are on the

157 same order of magnitude as the in-vitro affinities. This is obviously not correct (see above) and

158 converted values should therefore be used with caution.

159 We have optimized the experimental conditions in order to cover an affinity range 160 between $100 \mathrm{pm}$ and $10 \mu \mathrm{M}$. Thus, the couples BarstarY29F:BarnaseH102A and Grb2:Vav1

161 represent the minimal and maximal interaction strength that can be studied with these

162 experimental conditions. Stronger interactions lead to saturation and weaker interactions cannot 
163 be distinguished from noise. Not surprisingly the estimate of $K^{\prime}{ }_{\mathrm{d}}$ for couples

164 BarstarY29F:BarnaseH102A and Grb2:Vav1 is connected with the largest (relative) error (ca.

165 1; see Table S1, Supporting Information); most other couples feature relative errors between

1660.15 and 0.3 . To enable the study of interactions with apparent affinities in the lower picomolar 167 range, the experimental conditions need to be changed. The concentration of the AD-Prey 168 inducer (galactose), for example, could be decreased or the AD-Prey could be induced for less 169 than 2h. Similarly, the study of PPIs with weaker affinities than Grb2:Vav1 would require a 170 higher concentration of inducer or a longer induction period of Prey expression. (Conclusion)

The presented protocol is robust as witnessed by the small error bars in the titration curves (Fig. 1c) and the generally low relative error of $K^{\prime}{ }_{\mathrm{d}}$. All steps of the protocol have been optimized in liquid phase that can be easily automated for the use of microplates and integrated within robotic pipelines. It sets the stage for high-throughput affinity screenings of PPIs using cross-mating approaches ${ }^{[19,20]}$ with libraries of yeast clones. As an outlook, affinity-based networks ${ }^{[21]}$ can be created by attributing weights to the PPI edges according to their apparent

178 affinities. It contrasts standard $\mathrm{Y} 2 \mathrm{H}$ screens that yield networks with only binary information

179 (YES or NO). The topology of edge-weighted spring-embedded networks ${ }^{[22]}$ may help 180 identifying key pathways within the network, and how they change as a function of 181 environmental conditions (stress, metabolism, etc). Thus, we anticipate that high-throughput 182 qY2H affinity data would boost the modelling of interactomes and thereby advance 183 significantly systems biology.

\section{Methods}

Construction of the plasmids pSB_1Bait, pSB_1Prey and pBFP2 for the expression of BD-Bait, AD-Prey and the reported, respectively, has been described in detail elsewhere. ${ }^{[10]}$ 
188 Chemo-competent EGY42 (MATa; trp1, his3, ura3, leu2) and TB50 (MAT $\alpha$; trp1, his3, ura3,

189 leu2, rme1) yeasts were generated as previously described. ${ }^{[23]}$ The liquid-phase qY2H 190 experiments, acquisition by flow cytometry, conversion to units of $\operatorname{MESF}^{[24]}$ and statistical 191 analyses are described in the Supporting Information.

192 For the titration-like analysis we selected only yeast cells with a red fluorescence 193 intensity of $800 \pm 100$ in TagRFP-H channel, " $\mathrm{H}$ " indicates signal height. This red fluorescence 194 bin is located just above the $95 \%$ threshold of the non-fluorescent cells, ${ }^{[10]}$ and therefore defines $195 R_{\min }$. To ensure that these cells have been indeed transfected with all three vectors, we selected 196 for the analysis only large (=growing) cells with a forward scatter range $75000<$ FSC-H $<125$ 197000.

The mean Tag BFP-H value was then calculated for bins of varying $G$ values from -500 to 25500 yEGFP-H (bin size 1000). For each bin we calculated:

$$
\varphi(G)=\frac{\left\langle F_{\mathrm{BFP}, \text { interaction }}\right\rangle_{G}-\left\langle F_{\mathrm{BFP}, \mathrm{CTRL}}\right\rangle_{G}}{\left\langle F_{\mathrm{BFP}, \text { covalent }}\right\rangle_{G}-\left\langle F_{\mathrm{BFP}, \mathrm{CTRL}}\right\rangle_{G}}
$$

where $\left\langle F_{\mathrm{BFP}, \mathrm{X}}\right\rangle_{G}$ is the mean blue fluorescence intensity. The subscripted $\mathrm{X}$ refers to the physical interaction, covalent fusion or control couple. The control couple BD-Empty / ADEmpty $^{[10]}$ permits to remove the background of the reporter system.

Finally, $G$ values were converted into MESF of EGFP using calibration beads (Takara, reference 632594) following the manufacturer's protocol (see Supporting Information for more details). For the conversion of $R_{\min }$, we performed independent calibration measurements with diploid yeast cells expressing the fluorescent tandem fusion protein BD-TagRFP-yEGFP (under the same condition as the qY2H experiments). Cells with a red fluorescence intensity of $R_{\min }=$ $210800 \pm 100$ TagRFP-H displayed a mean green fluorescence intensity of 370000 MESF of 211 EGFP. 
213 averaged titration curves were least-square fitted with Eq. 1.

214

215 Acknowledgments

216 This work was supported by the Fonds Recherche of the Ecole Normale Supéreure de Lyon.

217

218 

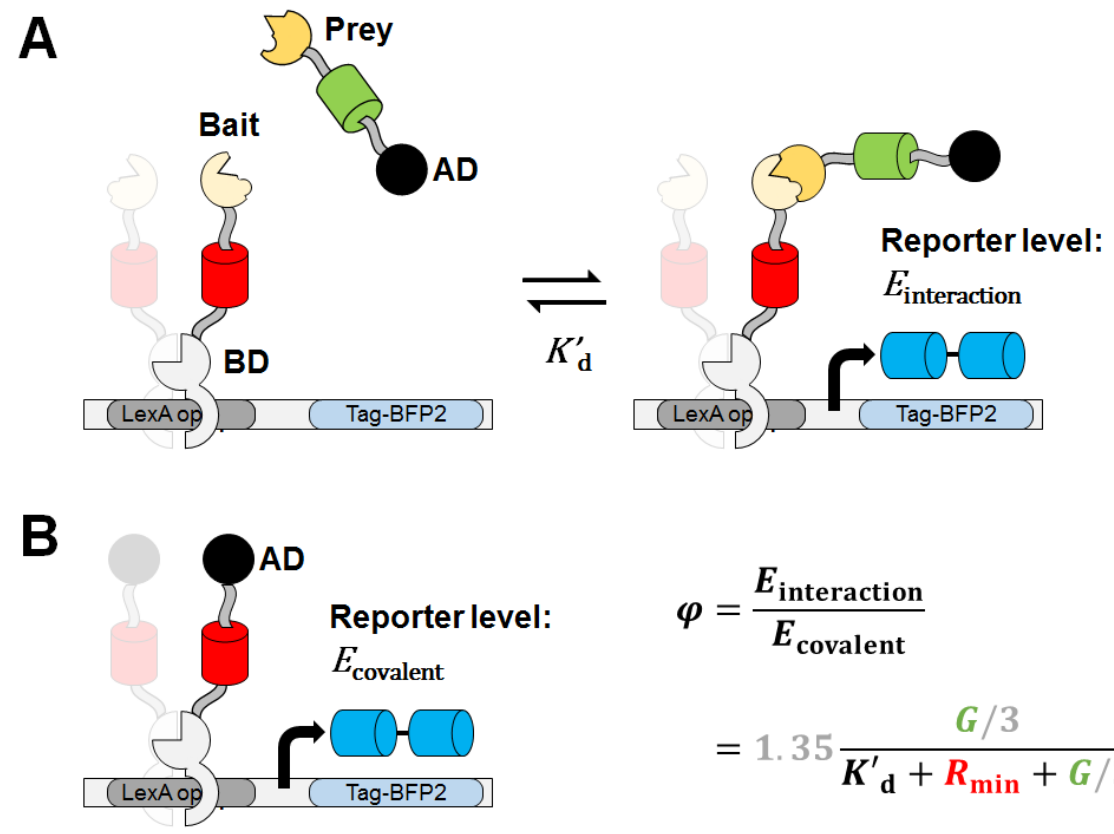
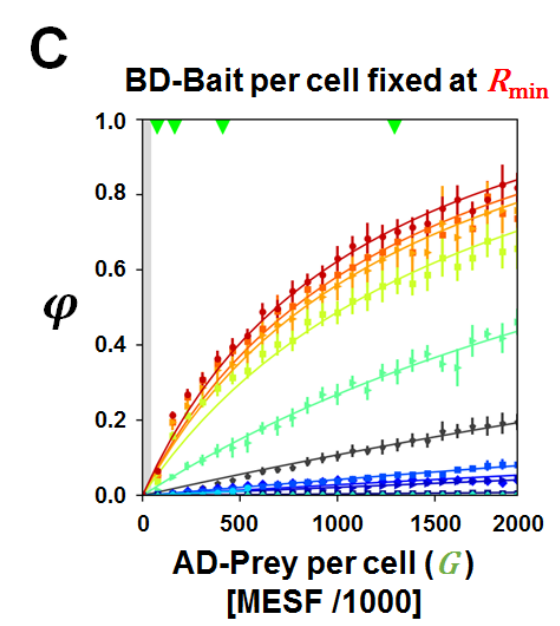

$$
\begin{aligned}
\boldsymbol{\varphi} & =\frac{\boldsymbol{E}_{\text {interaction }}}{\boldsymbol{E}_{\text {covalent }}} \\
& =1.35 \frac{G / 3}{\boldsymbol{K}_{\mathbf{d}}^{\prime}+\boldsymbol{R}_{\min }+G / 3}
\end{aligned}
$$

D

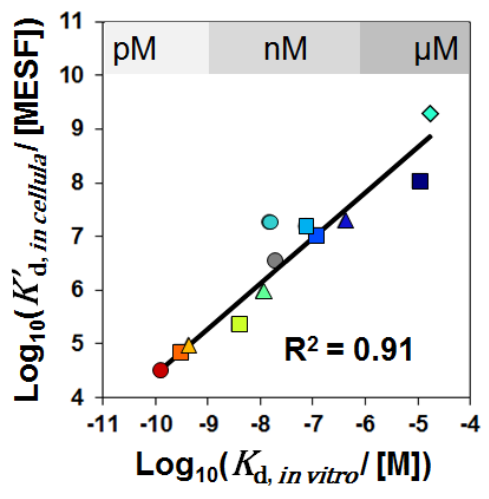

Figure 1: The qY2H system and its application to a titration-like analysis.

(A) In our qY2H system, red-fluorescent BD-Bait interacts with green-fluorescent AD-Prey to reconstitute a transcription factor that drives the expression of a blue-fluorescent reporter. Our hypothesis is that the expression level of the reporter, $E_{\text {interacting, }}$, reflects the number of $\mathrm{BD}$-molecules bound to the promoter corrected by the fraction of BD-Bait bound to AD-Prey. This fraction is influenced by the affinity between BD-Bait and AD-Prey, but also by their expression levels. (B) When the activation domain is covalently linked to the DNA-binding domain, the expression level $E_{\text {covalent }}$ depends only on the number of BD-Bait molecules bound the promoter. Thus, when forming the quantity $\varphi$ by dividing $E_{\text {interacting }}$ with $E_{\text {covalent }}$, we obtain a measure for the fraction of BD-molecules bound by an AD-Prey molecule. To determine $E_{\text {covalent }}$, we constructed a BD-AD fusion protein. Unfortunately, the activation domain B42 (as used in a) turned out to be toxic for our yeast strains when used in the BD-AD construct. Instead, we used the activation domain B112. Difference in the activation potential between B42 and B112 are integrated in the parameter $\beta$ of Eq. 1. (C) The quantity $\varphi$ can be monitored as a function of different levels of EGFP Molecules of Equivalent Soluble Fluorochrome (MESF) corresponding to different cellular levels of AD-Prey. In this titration-like analysis, the level of BD-Bait is kept fixed at the lowest possible value (see "Methods"). For the interaction TEM/BLIP1 (cyan line) the titration-like analysis can be performed only up to one third of the titrant quantity due to expression problems of AD-BLIP1 ${ }^{[10]}$ Green triangles at the top vertical axis indicate the position of used calibration beads. (D) When the titration curves are fitted with Eq. 1, we can extract the apparent dissociation constant in units of $\operatorname{MESF}\left(K_{\mathrm{d}}{ }^{\prime}\right)$. The estimated $K_{\mathrm{d}}$ '-values show a remarkable correlation with the dissociation constants measured from alternative in-vitro experiments (with matching symbols of Table 241 1). 
Table 1: Investigated protein-protein interactions and their in-vitro affinities $\left(K_{d}\right)$.

\begin{tabular}{|c|c|c|c|c|c|c|c|c|c|c|c|}
\hline \multicolumn{5}{|c|}{ Bait proteins } & \multirow[b]{2}{*}{$K_{\mathrm{d}}(\mathbf{p M})$} & \multirow[b]{2}{*}{ Symbol } & \multicolumn{5}{|c|}{ Prey proteins } \\
\hline Organism & Family & Name & Mutant & MW & & & Organism & Family & Name & Mutant & MW \\
\hline \multirow{6}{*}{$\begin{array}{l}\text { B. amylo- } \\
\text { liquefacien } \\
s\end{array}$} & \multirow{6}{*}{$\begin{array}{l}\text { RNAse } \\
\text { inhibitor }\end{array}$} & \multirow{6}{*}{ Barstar } & WT & 10 & $320^{\mathrm{a}}$ & $\square$ & \multirow{6}{*}{$\begin{array}{l}\text { B. amylo- } \\
\text { liquefaciens }\end{array}$} & \multirow{6}{*}{ RNAse } & \multirow{6}{*}{ Barnase } & \multirow{6}{*}{ H102A } & \multirow{6}{*}{12} \\
\hline & & & Y29A & 10 & $420^{\mathrm{a}}$ & $\triangle$ & & & & & \\
\hline & & & Y29F & 10 & $117^{\text {a }}$ & - & & & & & \\
\hline & & & W38F & 10 & $4000^{\mathrm{a}}$ & $\square$ & & & & & \\
\hline & & & D35A & 10 & $25000^{\mathrm{h}}$ & 0 & & & & & \\
\hline & & & D39A & 10 & $420000^{b}$ & $\Delta$ & & & & & \\
\hline \multirow{2}{*}{ H. sapiens } & \multirow{2}{*}{ GTPase } & \multirow{2}{*}{ HRas } & \multirow{2}{*}{$\begin{array}{l}\text { G12V \& } \\
\text { C186A }\end{array}$} & \multirow{2}{*}{21} & $122000^{\mathrm{c}}$ & $\square$ & \multirow{2}{*}{ H. sapiens } & \multirow{2}{*}{ Kinase } & \multirow{2}{*}{ CRaf RBD } & WT & 9 \\
\hline & & & & & $11000^{\mathrm{d}}$ & $\Delta$ & & & & A85K & 9 \\
\hline H. sapiens & $\begin{array}{l}\text { Kinase } \\
\text { regulatory } \\
\text { subunit }\end{array}$ & CksHs1 & WT & 10 & $77000^{\mathrm{e}}$ & $\square$ & H. sapiens & Kinase & CDK2 & WT & 34 \\
\hline E.coli & $\beta$-Lactamase & TEM & WT & 31 & $15000^{f}$ & O & S. clavuligerus & $\begin{array}{c}\beta \text {-Lactamase } \\
\text { inhibitor }\end{array}$ & BLIP1 & WT & 21 \\
\hline HIVI & $\begin{array}{l}\text { Virulence } \\
\text { factor }\end{array}$ & Nef & LAI & 23 & $11400000^{\mathrm{g}}$ & $\mathbf{\square}$ & H. sapiens & Kinase & SRC SH3 & WT & 7 \\
\hline H. sapiens & Adapter & Grb2 SH3 & WT & 7 & $17000000^{\mathrm{i}}$ & $\diamond$ & M. musculus & $\begin{array}{c}\text { Nucleotide } \\
\text { exchange } \\
\text { factor }\end{array}$ & Vav1 SH3 & WT & 8 \\
\hline
\end{tabular}

${ }^{\mathrm{a}} \mathrm{ITC}, 50 \mathrm{mM}$ Tris/ $\mathrm{HCl}, \mathrm{pH} 8$ at $25^{\circ} \mathrm{C} . .^{[25}$

${ }^{\mathrm{b}}$ Mean values from two studies ${ }^{[25,26]}$ with ITC, $24 \mathrm{mM}$ Hepes, $\mathrm{pH} 8,1 \mathrm{mM}$ DTT at $25^{\circ} \mathrm{C}$.

${ }^{\mathrm{c}}$ Mean values from four studies of Ras G12V (without the membrane anchor): SPR, $50 \mathrm{mM}$ Tris/HCl, $\mathrm{pH} 7.4,100 \mathrm{mM} \mathrm{NaCl}, 5 \mathrm{mM}$

$\mathrm{MgCl}_{2} ;{ }^{[27]} \mathrm{SPR}, 50 \mathrm{mM}$ Tris/ $\mathrm{HCl}, \mathrm{pH} 7.4,100 \mathrm{mM} \mathrm{NaCl}, 5 \mathrm{mM} \mathrm{MgCl}{ }_{2}{ }^{[28]} \mathrm{SPR}, 10 \mathrm{mM} \mathrm{Hepes,} \mathrm{pH} \mathrm{7.4,} 150 \mathrm{mM} \mathrm{NaCl}, 2 \mathrm{mM} \mathrm{MgCl} 2$, and $0.01 \%$ Nonidet P-40 $25^{\circ} \mathrm{C}$; ${ }^{[29]} \mathrm{ITC}, 50 \mathrm{mM}$ Hepes, $\mathrm{pH} 7.4,125 \mathrm{mM} \mathrm{NaCl}, 5 \mathrm{mM} \mathrm{MgCl}{ }_{2}, 25^{\circ} \mathrm{C}^{[30]}$

${ }^{\mathrm{d}}$ ITC, $50 \mathrm{mM}$ Hepes, pH 7.4, $125 \mathrm{mM} \mathrm{NaCl}, 5 \mathrm{mM} \mathrm{MgCl}_{2}, 25^{\circ} \mathrm{C}$. ${ }^{[30]}$ The dissociation constant of the CRaf RBD A85K mutant was measured with HRas WT loaded with a GTP-analogue. The mutant HRas G12V is known to decrease the dissociation constant for the interaction with CRaf RBD WT by a factor of 11. ${ }^{[31]}$ The given value applies the same correction factor.

${ }^{\mathrm{e}} \mathrm{SPR}, 10 \mathrm{mM}$ Hepes, $3.4 \mathrm{mM}$ EDTA, $150 \mathrm{mM} \mathrm{NaCl}, 0.001 \%$ surfactant P20, pH 7.4. ${ }^{[32]}$

${ }^{\mathrm{f}} \mathrm{SPR}, 10 \mathrm{mM}$ Hepes, $3.4 \mathrm{mM}$ EDTA, $150 \mathrm{mM} \mathrm{NaCl}, 0.05 \%$ surfactant P20, $\mathrm{pH}$ 7.4. ${ }^{[33]}$

${ }^{\mathrm{g}}$ ITC, $20 \mathrm{mM}$ phosphate buffer, $\mathrm{pH} 7.5,150 \mathrm{mM} \mathrm{NaCl}, 2 \mathrm{mM}$ EGTA, and $5 \mathrm{mM}$ DTT, $25^{\circ} \mathrm{C} .{ }^{[34]}$

${ }^{\mathrm{h}} \mathrm{SPR}, 10 \mathrm{mM}$ Hepes-Na, pH 7.4, 0.15 M NaCl, $3 \mathrm{mM}$ EDTA, and $0.005 \%$ (v/v) Tween 20, $25^{\circ} \mathrm{C}^{[35]}$

${ }^{\mathrm{i}} \mathrm{SPR}, 25^{\circ} \mathrm{C} .^{[36]}$

${ }^{\text {h }}$ Free-energy calculations. ${ }^{[10]}$ 
259 [1] J. Estojak, R. Brent, E. A. Golemis, Mol. Cell. Biol. 1995, 15, 5820-5829.

260 [2] H. Endoh, A. J. Walhout, M. Vidal, Methods Enzymol. 2000, 328, 74-88.

261 [3] N. Möckli, D. Auerbach, BioTechniques 2004, 36, 872-876.

262

263

264

265

266

267

268

[4] K. J. Jeong, M. J. Seo, B. L. Iverson, G. Georgiou, Proc. Natl. Acad. Sci. 2007, 104, 8247-8252.

[5] S. Dutta, A. Koide, S. Koide, J. Mol. Biol. 2008, 382, 721-733.

[6] K. Zolghadr, O. Mortusewicz, U. Rothbauer, R. Kleinhans, H. Goehler, E. E. Wanker, M. C. Cardoso, H. Leonhardt, Mol. Cell. Proteomics 2008, 7, 2279-2287.

[7] S. Fields, O. Song, Nature 1989, 340, 245-246.

[8] J. Gyuris, E. Golemis, H. Chertkov, R. Brent, Cell 1993, 75, 791-803.

[9] B. Stynen, H. Tournu, J. Tavernier, P. Van Dijck, Microbiol. Mol. Biol. Rev. 2012, 76, 331-382.

[10] D. Cluet, I. Amri, B. Vergier, J. Léault, A. Audibert, C. Grosjean, D. Calabrési, M. Spichty, Mol. Cell. Proteomics 2020, 19, 701-715.

[11] C. Bustamante, J. Liphardt, F. Ritort, Phys. Today 2005, 58, 43-48.

[12] J. Li, S. Wang, W. J. VanDusen, L. D. Schultz, H. A. George, W. K. Herber, H. J. Chae, W. E. Bentley, G. Rao, Biotechnol. Bioeng. 2000, 70, 187-196.

[13] B. Bolognesi, B. Lehner, eLife 2018, 7, e39804.

[14] S. V. Rajagopala, P. Uetz, in Netw. Biol. Methods Appl. (Eds.: G. Cagney, A. Emili), Humana Press, Totowa, NJ, 2011, pp. 1-29.

[15] T. D. Pollard, Mol. Biol. Cell 2010, 21, 4061-4067.

[16] X. Hu, S. Kang, X. Chen, C. B. Shoemaker, M. M. Jin, J. Biol. Chem. 2009, 284, 16369-16376.

[17] D. Younger, S. Berger, D. Baker, E. Klavins, Proc. Natl. Acad. Sci. 2017, 114, 1216612171.

[18] P. Colas, B. Cohen, P. K. Ferrigno, P. A. Silver, R. Brent, Proc. Natl. Acad. Sci. 2000, 97, 13720-13725.

[19] M. G. Kolonin, J. Zhong, R. L. Finley, Methods Enzymol. 2000, 328, $26-46$.

[20] J. Chen, M. B. Carter, B. S. Edwards, H. Cai, L. A. Sklar, Cytometry A 2012, 81A, 9098.

[21] K. Yugandhar, M. M. Gromiha, Curr. Protein Pept. Sci. 2016, 17, 72-81.

[22] T. Kamada, S. Kawai, Inf. Process. Lett. 1989, 31, 7-15.

[23] R. D. Gietz, R. H. Schiestl, Nat. Protoc. 2007, $2,1$.

[24] Information on "Flow cytometer calibration beads for AcGFP1/EGFP and mCherry," can be found under https://www.takarabio.com/products/gene-function/fluorescentproteins/flow-cytometer-calibration-beads.

[25] G. Schreiber, A. R. Fersht, J. Mol. Biol. 1995, 248, 478-486.

[26] C. Frisch, G. Schreiber, C. M. Johnson, A. R. Fersht, J. Mol. Biol. 1997, 267, 696-706.

[27] C. Herrmann, G. Horn, M. Spaargaren, A. Wittinghofer, J. Biol. Chem. 1996, 271, 6794-6800.

[28] C. Block, R. Janknecht, C. Herrmann, N. Nassar, A. Wittinghofer, Nat. Struct. Mol. Biol. 1996, 3, 244-251.

[29] A. Fischer, M. Hekman, J. Kuhlmann, I. Rubio, S. Wiese, U. R. Rapp, J. Biol. Chem. 2007, 282, 26503-26516.

[30] C. Kiel, D. Filchtinski, M. Spoerner, G. Schreiber, H. R. Kalbitzer, C. Herrmann, J. Biol. Chem. 2009, 284, 31893-31902.

[31] C. Kiel, Untersuchung von Ras/Effektor-Komplexen Mit Gezielt Veränderten Elektrostatischen Eigenschaftens, PhD Thesis, Dissertation, Ruhr-Universität Bochum, Fachbereich Biochemie, 2003. 
[32] Y. Bourne, M. H. Watson, M. J. Hickey, W. Holmes, W. Rocque, S. I. Reed, J. A. Tainer, Cell 1996, 84, 863-874.

[33] S. Albeck, G. Schreiber, Biochemistry (Mosc.) 1999, 38, 11-21. Biochemistry (Mosc.) 1998, 37, 14683-14691. Fujiki, T. Imanaka, H. Kato, J. Biol. Chem. 2008, 283, 6136-6144. 